\title{
THE EFFECT OF TRUST AND BRAND IMAGE ON PURCHASE DECREE (US TOYOTA CAR SURVEY IN JAKARTA REGION)
}

\author{
Setyo Ferry Wibowo \\ Fakultas Ekonomi Universitas Negeri Jakarta \\ E-mail: setyoferry@yahoo.com \\ Elsyana Purnama Sari \\ Fakultas Ekonomi Universitas Negeri Jakarta \\ E-mail: elsyana18@yahoo.com \\ Basrah Saidani \\ Fakultas Ekonomi Universitas Negeri Jakarta \\ E-mail: basrah_sp@yahoo.com
}

\begin{abstract}
The purpose of this research is to know: 1) influence of confidence to Toyota Agya car purchase decision in Jakarta area, and 2) influence of brand image to Toyota Agya car purchase decision in Jakarta area. The object of this research is 200 respondents of Toyota Agya car users in Jakarta area. Methods of data collection using survey method. Data analysis using SPSS 22. Descriptive test results explain that there is still a lack of trust and brand image in Toyota Agya car in the Jakarta area causing the lack of consumer response to make purchasing decisions. The result of hypothesis testing shows: 1) existence of positive and significant influence of trust toward purchasing decision, 2) existence of positive and significant influence from brand image to purchasing decision.
\end{abstract}

Keywords: trust, brand image, purchase decision, Toyota Agya, Jakarta 


\section{PENDAHULUAN}

Perkembangan bisnis pada era modern seperti saat ini membawa pengaruh besar dalam persaingan antar perusahaan baik di dalam maupun luar negeri. Tidak hanya perusahaan, tetapi produk yang dihasilkan juga semakin beragam. Perusahaan yang mengeluarkan produknya harus memiliki prospek usaha jangka panjang yang menjanjikan, seperti halnya dalam bidang transportasi. Ada tiga macam alat transportasi, yakni darat, laut dan udara. Transportasi memberikan kegunaan yaitu mempermudah perpindahan barang ataupun manusia ke tempat tujuan. Semakin berkembangnya transportasi yang mendukung saat ini, perusahaan yang bergerak dalam bidang otomotif harus memikirkan inovasi dan kreatifitas demi berlangsungnya proses ketepatan produksi dan ketertarikan konsumen untuk membeli dan menggunakannya, sehingga terciptanya alat transportasi yang efektif dan efisien.

Kementerian Perindustrian Perdagangan (2016), mengeluarkan peraturan bersama tentang impor kendaraan bermotor, baik dalam keadaan utuh (completely-built up, $C B U$ ) ataupun terurai (completely-knocked down, CKD), serta tentang industri perakitan dan keagenan. Pada tahun 2015, Indonesia merupakan salah satu negara dengan penjualan mobil tertinggi di ASEAN seperti yang tersaji pada tabel 1 di bawah.

Tabel 1. Data Penjualan Mobil di ASEAN tahun 2015

\begin{tabular}{cc}
\hline Negara ASEAN & Jumlah Penjualan \\
\hline Indonesia & 853.000 unit \\
\hline Thailand & 622.000 unit \\
\hline Malaysia & 541.000 unit \\
\hline Filiphina & 235.000 unit \\
\hline Vietnam & 165.000 unit \\
\hline Singapura & 62.000 unit \\
\hline Brunei Darrusalam & 12.000 unit
\end{tabular}

Sumber: katadata.co.id (2015)

Berikut data penjualan mobil berdasarkan data Gabungan Industri Kendaraan Bermotor Indonesia (Gaikindo) di Indonesia periode tahun 2014-2015. 
Tabel 2. Data Penjualan Wholesale Mobil Periode 2014-2015

\begin{tabular}{ccc}
\hline Brand & \multicolumn{2}{c}{ Penjualan Mobil Periode } \\
& $\mathbf{2 0 1 4}$ & $\mathbf{2 0 1 5}$ \\
\hline Toyota & 399,119 unit & 270.672 unit \\
\hline Daihatsu & 185,226 unit & 140.723 unit \\
\hline Honda & 159,147 unit & 132.458 unit \\
\hline Suzuki & 154,923 unit & 101.933 unit \\
\hline Mitsubishi & 141,962 unit & 97.227 unit \\
\hline
\end{tabular}

Sumber: otomotif.liputan6.com (2015)

Berdasarkan tabel di atas, penjualan terbesar masih dipegang kendaran low multi purpose vehicle (LMPV). Segmen yang diisi Avanza, Mobilio, Ertiga, dan Xenia ini berkontribusi sebesar 221.020 unit atau 25,9 persen dari total penjualan mobil di dalam negeri. Setelah LMPV, penjualan terbesar disumbang mobil berjenis city car dan LCGC sebesar 163.049 unit dan pikap menyumbang 166.643 unit. Sementara itu, Toyota masih menjadi merek mobil yang paling laris dengan penjualan 270.672, di tempat kedua ada Daihatsu dengan 150.723 unit dan Honda di posisi ketiga dengan 132.458 unit.

Pada hasil data brand index, Toyota Agya menduduki peringkat ketujuh. Hasil data tersebut menjelaskan bahwa Toyota Agya belum mencapai target pangsa pasar otomotif dalam kualitas mesin dan performa untuk digunakan jangka panjang.

Peneliti menanyakan kepada 100 responden pembeli mobil Toyota Agya baik baru saja memiliki atau yang sudah lama membeli mobil tersebut. Dari data yang masuk, hasil surveinya sebanyak 75 responden pembeli lama mobil Toyota Agya, sedangkan 25 responden adalah pengguna baru. Jadi, total yang dibutuhkan sebanyak 100 responden pembeli atau pemilik mobil Toyota Agya. Rata-rata pembeli mobil Toyota Agya ini adalah mahasiswa dan orang kantoran yang baru saja mempunyai penghasilan tetap.

\section{Rumusan Masalah}

1. Apakah kepercayaan konsumen berpengaruh positif dan signifikan terhadap keputusan pembelian Toyota Agya? 
2. Apakah citra merek Toyota Agya berpengaruh positif dan signifikan terhadap keputusan pembelian konsumen?

\section{Tujuan Penelitian}

1. Untuk mengetahui pengaruh kepercayaan terhadap keputusan pembelian mobil Toyota Agya.

2. Untuk mengetahui pengaruh citra merek terhadap keputusan pembelian mobil Toyota Agya.

\section{KAJIAN TEORITIK}

\section{Kepercayaan}

Menurut Prasaranphanich (2013:5) kepercayaan adalah "ketika konsumen mempercayai sebuah perusahaan, mereka akan lebih suka melakukan pembelian ulang dan membagi informasi pribadi yang berharga kepada perusahaan tersebut". Morgan dan Hunt (2013:248) berpendapat bahwa kepercayaan adalah "ketika suatu pihak mempunyai keyakinan bahwa pihak lain yang terlibat dalam pertukaran mempunyai reliabilitas dan integritas, maka dapat dikatakan ada kepercayaan (Darsono dan Dharmmesta, 2013)". Dari dua definisi di atas dapat disimpulkan bahwa kepercayaan adalah salah satu dasar untuk membeli barang berdasarkan empat indikator, yakni benevolence, integrity, competence, consistency.

\section{Citra Merek}

Menurut Kotler dan Keller (2014:263-264) brand image adalah gambaran mental atau konsep tentang sesuatu. Objek yang dimaksud berupa orang, organisasi, kelompok orang atau lainnya yang tidak diketahui. Image merupakan pandangan atau persepsi serta terjadinya proses akumulasi dari amanat kepercayaan yang diberikan oleh individu-individu, akan mengalami suatu proses cepat atau lambat membentuk suatu opini publik yang lebih luas dan abstrak.

Keller (2012:210) menyatakan bahwa citra merek bergantung pada sifat ekstrinsik dari produk atau layanan, termasuk cara-cara usaha suatu merek mempertemukan psikologis dan kebutuhan sosial pelanggan. Dengan demikian, 
citra lebih mengacu pada aspek intangible dari merek tersebut, dan pelanggan dapat mengasosiasikan bentuk citra secara langsung dari pengalaman mereka sendiri atau secara tidak langsung melalui iklan atau dari sumber informasi lain.

Dari kedua definisi citra merek di atas, dapat disimpulkan bahwa citra merek suatu produk merupakan gambaran atau cerminan dari produk brand yang akan dibeli oleh customer.

\section{Keputusan Pembelian}

Menurut Kotler (2016:163), keputusan pembelian yaitu beberapa tahapan yang dilakukan oleh konsumen sebelum melakukan keputusan pembelian suatu produk. Awater (2010) dalam Setiadi (2010) mendefinisikan pengambilan keputusan sebagai kegiatan mengumpulkan informasi tentang alternatif yang relevan dan membuat pilihan yang sesuai.

Dari definisi keputusan pembelian di atas dapat disimpulkan bahwa keputusan pembelian merupakan hal penting yang dilakukan konsumen dalam membeli suatu produk. Proses keputusan konsumen merupakan suatu kegiatan yang penting karena dalam proses tersebut memuat berbagai langkah yang terjadi secara berurutan sebelum konsumen mengambil keputusan.

\section{Model Penelitian}

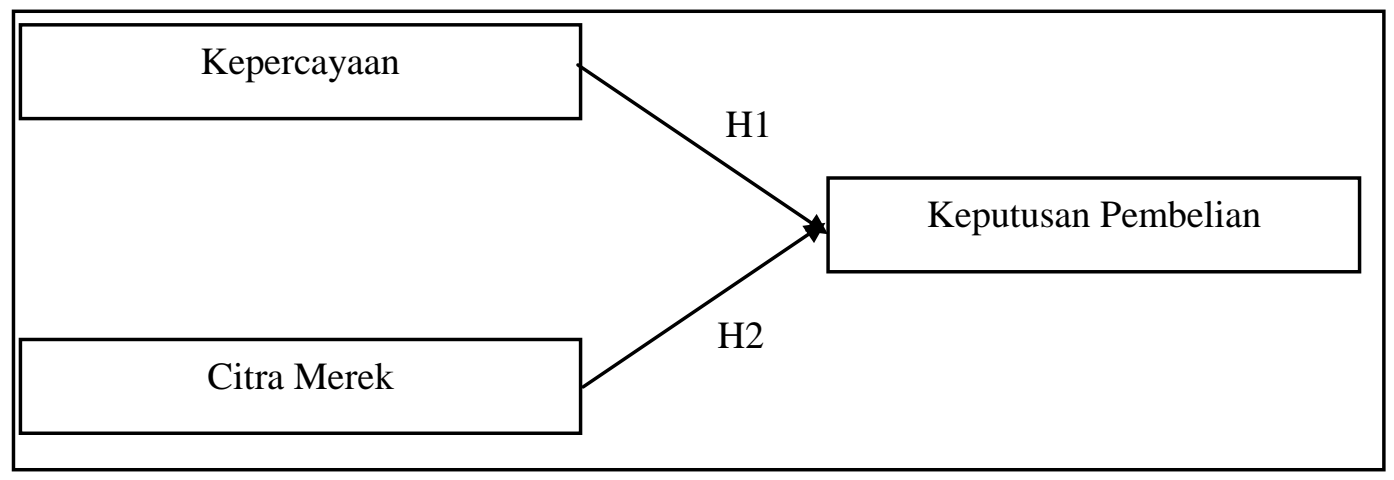

\section{Gambar 1. Model Penelitian}

Sumber: Data diolah oleh penulis (2017) 


\section{Hipotesis}

1. H1: Kepercayaan berpengaruh positif dan signifikan terhadap keputusan pembelian pengguna Toyota Agya.

2. H2: Citra merek berpengaruh positif dan signifikan terhadap keputusan pembelian pengguna Toyota Agya.

\section{METODE PENELITIAN}

Pendekatan yang digunakan dalam penelitian ini adalah penelitian kuantitatif dengan metode survei pengguna Toyota Agya di wilayah Jakarta. Desain penelitian explanatory dengan jenis penelitian deskriptif konklusif, yaitu peneliti akan melakukan pengujian terhadap hipotesis-hipotesis dan menguji pengaruh dari variabel independen terhadap variabel dependen (Malhotra, 2010:93). Populasi dalam penelitian ini adalah pengguna mobil Toyota Agya yang baru atau sudah lama menggunakan mobil tersebut. Jenis populasi yang akan diteliti adalah populasi infinite yaitu objek dengan ukuran yang tidak terhingga, yang mana peneliti dalam penelitian ini tidak mengetahui jumlah pasti pengguna mobil Toyota Agya yang berada di wilayah Jakarta maupun yang berdomisili di Jakarta. Jumlah sampel adalah 200 responden pengguna mobil Toyota Agya.

\section{HASIL PENELITIAN DAN PEMBAHASAN}

\section{Uji Instrumen}

\section{Uji Validitas}

Uji validitas digunakan untuk mengetahui sejauh mana ketepatan dan kecermatan suatu instrumen pengukuran dalam melakukan fungsi ukurnya yaitu agar data yang diperoleh bisa relevan/sesuai dengan tujuan diadakannya pengukuran tersebut (Malhotra, 2010:288). Dalam hal ini melakukan penelitian atau pengujian instrumen terlebih dahulu dengan jumlah sampel minimum 30 responden. 
Tabel 3. Hasil Uji Validitas

\begin{tabular}{|c|c|c|c|c|}
\hline Variabel & Butir & r-hitung & r-tabel & Ket. \\
\hline \multirow{8}{*}{ Kepercayaan } & BV 1 & 0,893 & 0,361 & Valid \\
\hline & BV 2 & 0,813 & 0,361 & Valid \\
\hline & IG 1 & 0,882 & 0,361 & Valid \\
\hline & IG 2 & 0,884 & 0,361 & Valid \\
\hline & $\mathrm{CP} 1$ & 0,814 & 0,361 & Valid \\
\hline & $\mathrm{CP} 2$ & 0,910 & 0,361 & Valid \\
\hline & $\mathrm{CS} 1$ & 0,931 & 0,361 & Valid \\
\hline & $\mathrm{CS} 2$ & 0,891 & 0,361 & Valid \\
\hline \multirow{16}{*}{ Citra Merek } & BP 1 & 0,920 & 0,361 & Valid \\
\hline & BP 2 & 0,819 & 0,361 & Valid \\
\hline & BI 1 & 0,939 & 0,361 & Valid \\
\hline & $\mathrm{BI} 2$ & 0,831 & 0,361 & Valid \\
\hline & BA 1 & 0,900 & 0,361 & Valid \\
\hline & BA 2 & 0,668 & 0,361 & Valid \\
\hline & BA 3 & 0,707 & 0,361 & Valid \\
\hline & BB 1 & 0,841 & 0,361 & Valid \\
\hline & BB 2 & 0,780 & 0,361 & Valid \\
\hline & $\mathrm{BC} 1$ & 0,870 & 0,361 & Valid \\
\hline & $\mathrm{BC} 2$ & 0,782 & 0,361 & Valid \\
\hline & $\mathrm{BC} 3$ & 0,795 & 0,361 & Valid \\
\hline & $\mathrm{AF} 1$ & 0,605 & 0,361 & Valid \\
\hline & $\mathrm{AF} 2$ & 0,683 & 0,361 & Valid \\
\hline & LY 1 & 0,806 & 0,361 & Valid \\
\hline & LY 2 & 0,843 & 0,361 & Valid \\
\hline \multirow{4}{*}{ Keputusan Pembelian } & DG 1 & 0,863 & 0,361 & Valid \\
\hline & DG 2 & 0,807 & 0,361 & Valid \\
\hline & CT 1 & 0,797 & 0,361 & Valid \\
\hline & CT 2 & 0,757 & 0,361 & Valid \\
\hline
\end{tabular}

Sumber: data diolah oleh Peneliti (2017)

Berdasarkan Tabel 3, syarat valid dengan jumlah responden 30 dengan tingkat signifikansi 5\% maka $\mathrm{r}$ tabel adalah 0,361, jadi hasil validitas harus melebihi 0,361 baru dinyatakan valid. 


\section{Uji Reliabilitas}

Reliabilitas adalah alat untuk mengukur tingkat kehandalan suatu kuesioner yang mengambarkan indikator dari variabel. Suatu kuesioner dikatakan reliabel atau handal jika jawaban seseorang terhadap pertanyaan adalah konsisten atau stabil dari waktu ke waktu (Priyatno, 2010:97). Untuk pengujian biasanya menggunakan batasan tertentu seperti 0,6. Reliabilitas kurang dari 0,6 kurang baik, sedangkan 0,7 dapat diterima, dan 0,8 adalah baik.

\section{Tabel 4. Hasil Uji Reliabilitas}

\begin{tabular}{ccc}
\hline Variabel & Cronbach's Alpha & Keterangan \\
\hline (X1) Kepercayaan & 0,957 & Reliabel \\
\hline (X2) Citra Merek & 0,961 & Reliabel \\
\hline (Y) Keputusan Pembelian & 0,820 & Reliabel \\
\hline Sumber: data diolah oleh Peneliti (2017) & &
\end{tabular}

Berdasarkan Tabel 4, variabel kepercayaan memiliki nilai sebesar 0,957, variabel citra merek sebesar 0,961 dan variabel keputusan pembelian sebesar 0,820. Jadi instrumen ketiga variabel dapat dinyatakan reliabel atau dapat dipercaya karena nilai Cronbach's Alpha lebih dari 0,6.

\section{Analisis Deskriptif}

Analisis deskriptif adalah analisis yang dilakukan untuk menggambarkan setiap jawaban yang diberikan responden yang berasal dari kuesioner yang telah dibuat (Sugiyono, 2012:88).

\section{Variabel Kepercayaan (X1)}

Tabel 5. Hasil Analisis Deskriptif Variabel Kepercayaan (X1)

\begin{tabular}{|c|c|c|c|c|c|c|}
\hline \multirow{2}{*}{$\begin{array}{c}\text { No } \\
\cdot\end{array}$} & \multirow{2}{*}{ Pernyataan } & \multicolumn{5}{|c|}{ Alternatif Jawaban } \\
\hline & & STS & TS & BS & $\mathbf{S}$ & SS \\
\hline \multicolumn{7}{|c|}{ Benevolence } \\
\hline \multirow{2}{*}{1} & \multirow{2}{*}{ Konsumen tertarik pada Toyota Agya } & 11 & 18 & 66 & 69 & 36 \\
\hline & & $5,5 \%$ & $9,0 \%$ & $33,0 \%$ & $34,5 \%$ & $18,0 \%$ \\
\hline \multirow{2}{*}{2} & \multirow{2}{*}{$\begin{array}{l}\text { Toyota Agya dapat diharapkan menjadi yang } \\
\text { terbaik }\end{array}$} & 8 & 17 & 61 & 91 & 23 \\
\hline & & $4,0 \%$ & $8,5 \%$ & $30,5 \%$ & $45,5 \%$ & $11,5 \%$ \\
\hline
\end{tabular}




\begin{tabular}{|c|c|c|c|c|c|c|}
\hline \multicolumn{7}{|c|}{ Integrity } \\
\hline \multirow{2}{*}{3} & \multirow{2}{*}{ Interior yang lengkap pada Toyota Agya } & 5 & 25 & 48 & 93 & 29 \\
\hline & & $2,5 \%$ & $12,5 \%$ & $24,0 \%$ & $46,5 \%$ & $14,5 \%$ \\
\hline \multirow{2}{*}{4} & \multirow{2}{*}{ Kehandalan dalam berkendara } & 8 & 24 & 54 & 82 & 32 \\
\hline & & $4,0 \%$ & $12,0 \%$ & $27,0 \%$ & $41,0 \%$ & $16,0 \%$ \\
\hline \multicolumn{7}{|c|}{ Competence } \\
\hline \multirow{2}{*}{5} & \multirow{2}{*}{$\begin{array}{l}\text { Kemampuan Toyota Agya dalam kecepatan } \\
\text { tinggi }\end{array}$} & 5 & 27 & 45 & 94 & 29 \\
\hline & & $2,5 \%$ & $13,5 \%$ & $22,5 \%$ & $47,0 \%$ & $14,5 \%$ \\
\hline \multirow{2}{*}{6} & \multirow{2}{*}{$\begin{array}{l}\text { Kemampuan Toyota Agya yang tidak } \\
\text { diragukan }\end{array}$} & 8 & 19 & 53 & 86 & 34 \\
\hline & & $4,0 \%$ & $9,5 \%$ & $26,5 \%$ & $43,0 \%$ & $17,0 \%$ \\
\hline \multicolumn{7}{|c|}{ Consistency } \\
\hline \multirow{2}{*}{7} & \multirow{2}{*}{$\begin{array}{l}\text { Toyota Agya termasuk mobil yang kuat dan } \\
\text { kokoh }\end{array}$} & 10 & 24 & 48 & 83 & 35 \\
\hline & & $5,0 \%$ & $12,0 \%$ & $24,0 \%$ & $41,5 \%$ & $17,5 \%$ \\
\hline \multirow{2}{*}{8} & \multirow{2}{*}{ Penyesuaian warna yang konsisten } & 11 & 20 & 60 & 78 & 31 \\
\hline & & $5,5 \%$ & $10,0 \%$ & $30,0 \%$ & $39,0 \%$ & $15,5 \%$ \\
\hline & Total Rata-Rata & $\begin{array}{c}4,1 \\
\%\end{array}$ & $\begin{array}{c}10,9 \\
\%\end{array}$ & $\begin{array}{c}27,2 \\
\%\end{array}$ & $\begin{array}{c}42,3 \\
\%\end{array}$ & $\begin{array}{c}15,6 \\
\%\end{array}$ \\
\hline
\end{tabular}

Sumber: data diolah oleh Peneliti (2017)

Berdasarkan analisis deskriptif variabel kepercayaan pada dimensi benevolence, pertanyaan nomor satu dan dua menjelaskan bahwa alternatif jawaban setuju mendapat respon terbanyak sebesar 33,0\% dan 45,5\%. Pada dimensi integrity variabel kepercayaan, pertanyaan nomor tiga dan empat menjelaskan bahwa alternatif jawaban setuju mendapat respon terbanyak sebesar 46,5\% dan 41,0\%. Dimensi competence variabel kepercayaan, pertanyaan nomor lima dan enam menjelaskan bahwa alternatif jawaban setuju mendapat respon terbanyak sebesar 47,0\% dan 43,0\%. Dimensi consistency variabel kepercayaan, pertanyaan nomor tujuh dan delapan menjelaskan bahwa alternatif jawaban setuju mendapat respon terbanyak sebesar $41,5 \%$ dan $39,0 \%$.

\section{Variabel Citra Merek (X2)}

Tabel 6. Hasil Analisis Deskriptif Variabel Citra Merek (X2)

\begin{tabular}{cccccccc}
\hline \multirow{2}{*}{ No. } & Pernyataan & \multicolumn{7}{c}{ Alternatif Jawaban } \\
\cline { 3 - 7 } & & STS & TS & BS & S & SS \\
\hline \multicolumn{8}{c}{ Brand Personality } \\
\hline 1 & Toyota Agya menjunjung tinggi & 8 & 21 & 22 & 116 & 33 \\
\hline
\end{tabular}




\begin{tabular}{|c|c|c|c|c|c|c|}
\hline & nilai-nilai ramah lingkungan & $4,0 \%$ & $10,5 \%$ & $11,0 \%$ & $58,0 \%$ & $16,5 \%$ \\
\hline \multirow{2}{*}{2} & \multirow{2}{*}{$\begin{array}{l}\text { Toyota Agya termasuk mobil } \\
\text { yang canggih }\end{array}$} & 11 & 17 & 12 & 139 & 21 \\
\hline & & $5,5 \%$ & $8,5 \%$ & $6,0 \%$ & $69,5 \%$ & $10,5 \%$ \\
\hline \multicolumn{7}{|c|}{ Brand Identity } \\
\hline \multirow{2}{*}{3} & \multirow{2}{*}{ Logo Toyota Agya mudah dikenal } & 9 & 40 & 32 & 90 & 29 \\
\hline & & $4,5 \%$ & $20,0 \%$ & $16,0 \%$ & $45,0 \%$ & $14,5 \%$ \\
\hline \multirow{2}{*}{4} & \multirow{2}{*}{$\begin{array}{l}\text { Slogan Toyota Agya yang } \\
\text { menarik }\end{array}$} & 12 & 27 & 15 & 122 & 24 \\
\hline & & $6,0 \%$ & $13,5 \%$ & $7,5 \%$ & $61,0 \%$ & $12,0 \%$ \\
\hline \multicolumn{7}{|c|}{ Brand Association } \\
\hline \multirow{2}{*}{5} & \multirow{2}{*}{$\begin{array}{l}\text { Iklan mobil Toyota Agya yang } \\
\text { bersahabat }\end{array}$} & 8 & 43 & 24 & 83 & 42 \\
\hline & & $4,0 \%$ & $21,5 \%$ & $12,0 \%$ & $41,5 \%$ & $21,0 \%$ \\
\hline \multirow{2}{*}{6} & \multirow{2}{*}{ Mobil Toyota Agya berkualitas } & 9 & 58 & 18 & 84 & 31 \\
\hline & & $4,5 \%$ & $29,0 \%$ & $9,0 \%$ & $42,0 \%$ & $15,5 \%$ \\
\hline \multirow{2}{*}{7} & \multirow{2}{*}{$\begin{array}{l}\text { Mobil Toyota Agya sebagai mobil } \\
\text { murah }\end{array}$} & 15 & 32 & 40 & 79 & 34 \\
\hline & & $7,5 \%$ & $16,0 \%$ & $20,0 \%$ & $39,5 \%$ & $17,0 \%$ \\
\hline \multicolumn{7}{|c|}{ Brand Attitude and Behavior } \\
\hline \multirow{2}{*}{8} & \multirow{2}{*}{$\begin{array}{l}\text { Mobil Toyota Agya mudah } \\
\text { digunakan }\end{array}$} & 11 & 52 & 23 & 90 & 24 \\
\hline & & $5,5 \%$ & $26,0 \%$ & $11,5 \%$ & $45,0 \%$ & $12,0 \%$ \\
\hline \multirow{2}{*}{9} & \multirow{2}{*}{$\begin{array}{l}\text { Mobil Toyota Agya nyaman saat } \\
\text { dikendarai }\end{array}$} & 13 & 14 & 17 & 118 & 38 \\
\hline & & $6,5 \%$ & $7,0 \%$ & $8,5 \%$ & $59,0 \%$ & $19,0 \%$ \\
\hline \multicolumn{7}{|c|}{ Brand Benefit and Competence } \\
\hline \multirow{2}{*}{10} & \multirow{2}{*}{$\begin{array}{l}\text { Mobil Toyota Agya dapat } \\
\text { menambah kepercayaan diri } \\
\text { pengendara }\end{array}$} & 11 & 58 & 40 & 78 & 13 \\
\hline & & $5,5 \%$ & $29,0 \%$ & $20,0 \%$ & $39,0 \%$ & $6,5 \%$ \\
\hline \multirow{2}{*}{11} & \multirow{2}{*}{$\begin{array}{l}\text { Mobil Toyota Agya memudahkan } \\
\text { penggunanya sebagai alat } \\
\text { transportasi }\end{array}$} & 12 & 28 & 16 & 114 & 30 \\
\hline & & $6,0 \%$ & $14,0 \%$ & $8,0 \%$ & $57,0 \%$ & $15,0 \%$ \\
\hline \multirow{2}{*}{12} & \multirow{2}{*}{$\begin{array}{l}\text { Mobil Toyota Agya cocok untuk } \\
\text { anak muda }\end{array}$} & 11 & 42 & 19 & 101 & 27 \\
\hline & & $5,5 \%$ & $21,0 \%$ & $9,5 \%$ & $50,5 \%$ & $13,5 \%$ \\
\hline \multirow{3}{*}{13} & & Affinity & & & & \\
\hline & Mobil Toyota Agya digemari & 11 & 20 & 15 & 127 & 27 \\
\hline & semua kalangan & $5,5 \%$ & $10,0 \%$ & $7,5 \%$ & $63,5 \%$ & $13,5 \%$ \\
\hline 14 & Saya akan membicarakan hal-hal & 14 & 31 & 18 & 111 & 26 \\
\hline 14 & $\begin{array}{l}\text { baik tentang mobil Toyota Agya } \\
\text { kepada orang lain }\end{array}$ & $7,0 \%$ & $15,5 \%$ & $9,0 \%$ & $55,5 \%$ & $13,0 \%$ \\
\hline & & Loyalty & & & & \\
\hline 15 & Responden mobil Toyota Agya & 8 & 30 & 31 & 93 & 38 \\
\hline 15 & setia pada tipe mobil ini & $4,0 \%$ & $15,0 \%$ & $15,5 \%$ & $46,5 \%$ & $19,0 \%$ \\
\hline 16 & Mobil Toyota Agya memberikan & 16 & 36 & 1 & 118 & 29 \\
\hline 10 & $\begin{array}{l}\text { penyajian interior dan eksterior } \\
\text { yang rapi }\end{array}$ & $8,0 \%$ & $18,0 \%$ & $0,5 \%$ & $59,0 \%$ & $14,5 \%$ \\
\hline & Total Rata-Rata & $5,6 \%$ & $16,6 \%$ & $10,6 \%$ & $52,4 \%$ & $14,8 \%$ \\
\hline
\end{tabular}

Sumber: data diolah oleh Peneliti (2017) 
Berdasarkan analisis deskriptif dimensi brand personality dari variabel citra merek, pada alternatif jawaban pertanyaan nomor satu dan dua mendapat respon terbanyak adalah setuju, yaitu dengan persentase 58,0\% dan 69,5\%. Sedangkan dimensi brand identity pada pertanyaan nomor tiga dan empat, alternatif jawaban setuju mendapat predikat respon terbanyak sebesar 45,0\% dan $61,0 \%$.

Dimensi brand association pada pertanyaan nomor lima, enam dan tujuh, alternatif jawaban setuju mendapat respon terbanyak sebesar 41,5\%, 42,0\% dan 39,5\%. Dimensi brand attitude and behavior pada pertanyaan nomor delapan dan sembilan, alternatif jawaban setuju mendapat respon terbanyak sebesar 45,0\% dan 59,0\%. Dimensi brand benefit and competence pada pertanyaan nomor sepuluh, sebelas dan dua belas, alternatif jawaban setuju mendapat respon terbanyak sebesar $39,0 \%, 57,0 \%$ dan $50,5 \%$.

Dimensi affinity pada pertanyaan nomor tiga belas dan empat belas, alternatif jawaban setuju mendapat respon terbanyak sebesar $63,5 \%$ dan 55,5\%. Dimensi terakhir yakni dimensi loyalty pada pertanyaan nomor lima belas dan enam belas, alternatif jawaban setuju mendapat respon terbanyak sebesar 46,5\% dan $59,0 \%$.

\section{Variabel Keputusan Pembelian (Y)}

Tabel 7. Hasil Analisis Deskriptif Variabel Keputusan Pembelian (Y)

\begin{tabular}{|c|c|c|c|c|c|c|}
\hline \multirow{2}{*}{ No. } & \multirow{2}{*}{ Pernyataan } & \multicolumn{5}{|c|}{ Alternatif Jawaban } \\
\hline & & STS & TS & BS & $\mathbf{S}$ & SS \\
\hline \multicolumn{7}{|c|}{ Degree } \\
\hline \multirow{2}{*}{1} & \multirow{2}{*}{$\begin{array}{l}\text { Responden sepakat untuk mengambil } \\
\text { keputusan pembelian dan } \\
\text { merekomendasikannya }\end{array}$} & 3 & 28 & 68 & 72 & 29 \\
\hline & & $1,5 \%$ & $14,0 \%$ & $34,0 \%$ & $36,0 \%$ & $14,5 \%$ \\
\hline \multirow{2}{*}{2} & \multirow{2}{*}{$\begin{array}{l}\text { Suku cadang yang digunakan lebih } \\
\text { mudah dijumpai }\end{array}$} & 2 & 19 & 67 & 77 & 35 \\
\hline & & $1,0 \%$ & $9,5 \%$ & $33,5 \%$ & $38,5 \%$ & $17,5 \%$ \\
\hline \multirow{3}{*}{3} & \multirow{3}{*}{$\begin{array}{l}\text { Pencarian informasi mengenai mobil } \\
\text { Toyota Agya mudah dilakukan }\end{array}$} & Content & & & & \\
\hline & & 3 & 23 & 63 & 79 & 32 \\
\hline & & $1,5 \%$ & $11,5 \%$ & $31,5 \%$ & $39,5 \%$ & $16,0 \%$ \\
\hline \multirow{3}{*}{4} & \multirow{2}{*}{$\begin{array}{l}\text { Mobil Toyota Agya dapat dijumpai di } \\
\text { berbagai tempat }\end{array}$} & 1 & 32 & 69 & 74 & 24 \\
\hline & & $0,5 \%$ & $16,0 \%$ & $34,5 \%$ & $37,0 \%$ & $12,0 \%$ \\
\hline & Total Rata-Rata & $1,1 \%$ & $12,8 \%$ & $33,4 \%$ & $37,8 \%$ & $15,0 \%$ \\
\hline
\end{tabular}

Sumber: data diolah Peneliti (2017) 
Berdasarkan dimensi degree pada variabel keputusan pembelian, pertanyaan nomor satu dan dua alternatif jawaban setuju mendapat respon terbanyak sebesar 36,0\% dan 38,5\%. Dimensi content pada pertanyaan nomor tiga dan empat, alternatif jawaban setuju mendapat respon terbanyak sebesar 39,5\% dan $37,0 \%$.

\section{Hasil Uji Asumsi Klasik}

\section{Uji Normalitas}

Uji normalitas bertujuan untuk menguji apakah dalam model regresi, variabel pengganggu atau residual memiliki distribusi normal. Penelitian ini menggunakan one-sample Kolmogorov-smirnov test dengan menggunakan taraf signifikan sebesar 0,005. Data dinyatakan berdistrubusi normal jika signifikannya lebih dari 0,05 (Albert, 2014:132).

Tabel 8. Hasil Uji Normalitas

\begin{tabular}{|c|c|c|c|c|}
\hline \multicolumn{5}{|c|}{ One-Sample Kolmogorov-Smirnov Test } \\
\hline & & Kepercayaan & Citra Merek & $\begin{array}{l}\text { Keputusan } \\
\text { Pembelian }\end{array}$ \\
\hline $\mathrm{N}$ & & 200 & 200 & 200 \\
\hline \multirow{2}{*}{ Normal Parameters ${ }^{a, b}$} & Mean & 3,5425 & 3,5275 & 5,6440 \\
\hline & Std. Deviation & ,87356 & ,88514 & 1,31831 \\
\hline \multirow[t]{3}{*}{ Most Extreme Differences } & Absolute &, 053 &, 054 &, 062 \\
\hline & Positive &, 048 & ,048 &, 058 \\
\hline & Negative &,- 053 &,- 054 &,- 062 \\
\hline Test Statistic & &, 053 & ,054 &, 062 \\
\hline Asymp. Sig. (2-tailed) & & 200 & ,200 &, 060 \\
\hline
\end{tabular}

Sumber: data diolah oleh Peneliti (2017)

Pada hasil penelitian ini, variabel kepercayaan memiliki nilai signifikansi sebesar 0,200, variabel citra merek memiliki nilai signifikansi sebesar 0,200 dan variabel keputusan pembelian memiliki nilai signifikansi sebesar 0,060. Maka keseluruhan variabel pada penelitian ini normal, karena memiliki nilai signifikansi lebih dari 0,05 . 


\section{Uji Residual}

Tabel 9. Hasil Uji Residual

\begin{tabular}{|c|c|c|}
\hline \multicolumn{3}{|c|}{ One-Sample Kolmogorov-Smirnov Test } \\
\hline & & $\begin{array}{c}\text { Unstandardized } \\
\text { Residual }\end{array}$ \\
\hline $\mathrm{N}$ & & 200 \\
\hline \multirow[t]{2}{*}{ Normal Parameters ${ }^{a, b}$} & Mean &, 0000000 \\
\hline & Std. Deviation & ,95880500 \\
\hline \multirow[t]{3}{*}{ Most Extreme Differences } & Absolute &, 069 \\
\hline & Positive & ,049 \\
\hline & Negative &,- 069 \\
\hline Kolmogorov-Smirnov Z & & ,975 \\
\hline Asymp. Sig. (2-tailed) & & 298 \\
\hline
\end{tabular}

Sumber: data diolah oleh Peneliti (2017)

Untuk mengetahui normalitas regresi digunakan data unstandardized residual, diperoleh nilai Kolmogorov-Smirnov sebesar 0,975, sedangkan nilai probabilitas diperoleh sebesar 0,298 yang lebih besar dari taraf kesalahan yaitu 0,05 , maka dinyatakan model regresi berdistribusi normal.

\section{Uji Linieritas}

Uji linieritas bertujuan untuk mengetahui apakah dua variabel mempunyai hubungan yang linear atau tidak secara signifikan (Ghozali, 2012:97). Uji ini biasanya digunakan sebagai prasyarat dalam analisis korelasi atau regresi linear. Pengujian pada SPSS dengan menggunakan Test for Linearity dengan pada taraf signifikansi 0,05 . Dua variabel dikatakan mempunyai hubungan yang linear bila signifikansi (Linearity) kurang dari 0,05.

Tabel 10. Hasil Uji Linieritas Variabel Kepercayaan $\left(\mathrm{X}_{1}\right)$ dengan Variabel Keputusan Pembelian (Y)

\begin{tabular}{|c|c|c|c|c|c|c|c|}
\hline \multicolumn{8}{|c|}{ ANOVA Table } \\
\hline & & & $\begin{array}{l}\text { Sum of } \\
\text { Squares }\end{array}$ & $\mathrm{df}$ & $\begin{array}{l}\text { Mean } \\
\text { Square }\end{array}$ & $\mathrm{F}$ & Sig. \\
\hline \multirow{5}{*}{$\begin{array}{l}\text { Keputusan } \\
\text { Pembelian * } \\
\text { Kepercayaan }\end{array}$} & Between & (Combined) & 169,890 & 32 & 5,309 & 5,039 &, 000 \\
\hline & Groups & Linearity & 130,410 & 1 & 130,410 & 123,768 &, 000 \\
\hline & & $\begin{array}{l}\text { Deviation from } \\
\text { Linearity }\end{array}$ & 39,480 & 31 & 1,274 & 1,209 & ,223 \\
\hline & Within G & & 175,963 & 167 & 1,054 & & \\
\hline & Total & & 345,853 & 199 & & & \\
\hline
\end{tabular}

Sumber: data diolah oleh Peneliti (2017) 
Berdasarkan hasil di atas menjelaskan bahwa linearity dengan nilai signifikansi sebesar 0,000. Karena kurang dari 0,05 maka variabel kepercayaan dan keputusan pembelian dapat disimpulkan memiliki hubungan linier.

Tabel 11. Hasil Uji Linieritas Variabel Citra Merek (X2) dengan Variabel Keputusan Pembelian (Y)

\begin{tabular}{|c|c|c|c|c|c|c|c|}
\hline \multicolumn{8}{|c|}{ ANOVA Table } \\
\hline & & & $\begin{array}{l}\text { Sum of } \\
\text { Squares }\end{array}$ & $d f$ & $\begin{array}{l}\text { Mean } \\
\text { Square }\end{array}$ & $\mathrm{F}$ & Sig. \\
\hline \multirow{5}{*}{$\begin{array}{l}\text { Keputusan } \\
\text { Pembelian * Citra } \\
\text { Merek }\end{array}$} & Between & (Combined) & 179,418 & 63 & 2,848 & 2,327 &, 000 \\
\hline & Groups & Linearity & 93,299 & 1 & 93,299 & 76,238 &, 000 \\
\hline & & $\begin{array}{l}\text { Deviation from } \\
\text { Linearity }\end{array}$ & 86,120 & 62 & 1,389 & 1,135 & ,269 \\
\hline & Within $C$ & & 166,435 & 136 & 1,224 & & \\
\hline & Total & & 345,853 & 199 & & & \\
\hline
\end{tabular}

Sumber: data diolah oleh Peneliti (2017)

Berdasarkan hasil di atas menjelaskan bahwa linearity dengan nilai signifikansi sebesar 0,000. Karena kurang dari 0,05 maka variabel citra merek dan keputusan pembelian dapat disimpulkan memiliki hubungan linier.

\section{Uji Multikolinieritas}

Penelitian ini melakukan uji multikolinieritas dengan tujuan melihat keadaan dimana antara dua variabel bebas atau lebih pada model regresi terjadi di hubungan linier yang sempurna atau mendekati sempurna (Albert, 2014:157). Model regresi yang baik menyaratkan tidak adanya masalah multikolineritas. Multikolinieritas dapat melihat adanya VIF atau Value Inflation Factor pada model regresi di tabel coefficients, jika nilai VIF kurang dari 10 maka variabel tersebut tidak mempunyai masalah multikolinearitas dengan variabel bebas lainnya dan jika nilai tolerance lebih dari 0,1 maka tidak terjadi multikolineritas.

Tabel 12. Hasil Uji Multikolinieritas

\begin{tabular}{|c|c|c|c|}
\hline \multicolumn{4}{|c|}{ Coefficients $^{a}$} \\
\hline & & \multicolumn{2}{|c|}{ Collinearity Statistics } \\
\hline Model & & Tolerance & VIF \\
\hline \multirow[t]{2}{*}{1} & Kepercayaan &, 852 & 1,174 \\
\hline & Citra Merek &, 852 & 1,174 \\
\hline
\end{tabular}

Sumber: data diolah oleh Peneliti (2017) 
Berdasarkan hasil uji multikolinieritas bahwa hasil dari variabel kepercayaan sebesar 1,174 dan citra merek sebesar 1,174. Hasil tersebut kurang dari 10, maka disimpulkan bahwa model regresi tidak ditemukan adanya masalah multikolinieritas karena nilai VIF kurang dari 10. Melihat nilai tolerance lebih dari 0,1 yakni untuk variabel kepercayaan sebesar 0,852 dan citra merek sebesar 0,852 .

\section{Uji Heterokedastisitas}

Uji heterokedastisitas adalah uji yang menilai apakah ada ketidaksamaan varian dari residual untuk semua pengamatan pada model regresi linear (Albert, 2014:139). Apabila asumsi heterokedastisitas tidak terpenuhi, maka model regresi dinyatakan tidak valid sebagai alat peramalan. Pada penelitian ini menggunakan analisis uji spearman's rho dengan menkorelasikan nilai residual dengan masingmasing variabel penelitian, dengan syarat apabila signifikan korelasinya lebih besar dari 0,05 maka pada model regresi tidak terjadi heterokedastisitas.

Tabel 13. Hasil Uji Heterokedastisitas

\begin{tabular}{|c|c|c|c|c|c|}
\hline \multicolumn{6}{|c|}{ Correlations } \\
\hline & & & \multicolumn{2}{|l|}{ Unstandardized } & \multirow{2}{*}{$\begin{array}{l}\text { Citra } \\
\text { Merek }\end{array}$} \\
\hline & & & Residual & Kepercayaan & \\
\hline \multirow{12}{*}{$\begin{array}{l}\text { Spearman's } \\
\text { rho }\end{array}$} & Unstandardized & Correlation & $100 \Omega$ & 067 & 014 \\
\hline & Residual & Coefficient & 1,000 & , & \\
\hline & & Sig. (2-tailed) & . & ,348 & ,849 \\
\hline & & $\mathrm{N}$ & 200 & 200 & 200 \\
\hline & Kepercayaan & Correlation & 067 & 1000 & $358^{* * *}$ \\
\hline & & Coefficient & , & 1,000 & , \\
\hline & & Sig. (2-tailed) & ,348 & . & ,000 \\
\hline & & $\mathrm{N}$ & 200 & 200 & 200 \\
\hline & Citra Merek & Correlation & 014 & $25{ }^{\circ * * *}$ & 1000 \\
\hline & & Coefficient & , & & 1,000 \\
\hline & & Sig. (2-tailed) & ,849 & ,000 & . \\
\hline & & $\mathrm{N}$ & 200 & 200 & 200 \\
\hline
\end{tabular}

Sumber: data diolah oleh Peneliti (2017) 
Dari tabel di atas dapat diketahui nilai signifikansi variabel kepercayaan $\left(\mathrm{X}_{1}\right)$ sebesar 0,348 dan variabel citra merek $\left(\mathrm{X}_{2}\right)$ sebesar 0,849. Karena nilai signifikansinya lebih dari 0,05 maka dapat disimpulkan tidak terjadi masalah heteroskedastisitas.

\section{Uji Hipotesis}

\section{Regresi Linier Berganda}

Tabel 14. Hasil Regresi Linier Berganda

\begin{tabular}{|c|c|c|c|c|c|c|}
\hline \multicolumn{7}{|c|}{ Coefficients $^{a}$} \\
\hline \multirow[b]{2}{*}{ Model } & & \multicolumn{2}{|c|}{ Unstandardized Coefficients } & $\begin{array}{c}\text { Standardized } \\
\text { Coefficients }\end{array}$ & \multirow[b]{2}{*}{$\mathrm{t}$} & \multirow[b]{2}{*}{ Sig. } \\
\hline & & $\mathrm{B}$ & Std. Error & Beta & & \\
\hline \multirow[t]{3}{*}{1} & (Constant) & 1,300 & ,337 & & 3,857 & ,000 \\
\hline & Kepercayaan & ,734 & ,085 & ,486 & 8,658 & ,000 \\
\hline & Citra Merek & ,495 & ,084 &, 332 & 5,916 &, 000 \\
\hline
\end{tabular}

Sumber: data diolah oleh Peneliti (2017)

Persamaan diatas dapat dijelaskan konstanta sebesar 1,300 artinya jika variabel kepercayaan $\left(\mathrm{X}_{1}\right)$, citra merek $\left(\mathrm{X}_{2}\right)$ bernilai 0 , maka keputusan pembelian (Y) akan bernilai 1,300. Koefisien regresi variabel kepercayaan $\left(\mathrm{X}_{1}\right)$ sebesar 0,734 artinya jika variabel dimensi kepercayaan mengalami kenaikan satu-satuan dan nilai variabel citra merek $\left(\mathrm{X}_{2}\right)$ tetap, maka variabel keputusan pembelian $(\mathrm{Y})$ akan mengalami kenaikkan sebesar 0,734. Koefisien bernilai positif artinya terjadi pengaruh positif antara variabel kepercayaan $\left(\mathrm{X}_{1}\right)$ terhadap variabel keputusan pembelian (Y).

Koefisien regresi variabel citra merek $\left(\mathrm{X}_{2}\right)$ sebesar 0,495 artinya jika variabel citra merek $\left(\mathrm{X}_{2}\right)$ mengalami kenaikan satu-satuan dan nilai variabel kepercayaan $\left(\mathrm{X}_{1}\right)$ tetap, maka variabel keputusan pembelian $(\mathrm{Y})$ akan mengalami kenaikan sebesar 0,495 . Koefisien bernilai positif artinya pengaruh positif antara variabel citra merek $\left(\mathrm{X}_{2}\right)$ terhadap variabel keputusan pembelian $(\mathrm{Y})$.

\section{Uji t}

Uji t digunakan untuk menguji pengaruh variabel bebas terhadap variabel terikat secara sendiri-sendiri (Kuncoro, 2007:81). Hasil uji t dapat diliihat pada tabel Anova, jika hasil uji t nilai signifikannya kurang dari 0,05 maka variabel 
bebas tersebut dinyatakan mempengaruhi variabel terikat, jika hasilnya lebih dari 0,05 maka variabel bebas tersebut dinyatakan tidak mempengaruhi variabel terikat secara parsial atau sendiri-sendiri, namun juga harus melihat tabel uji $t$, tabel dapat dilihat pada signifikansi $0,05 / 2=0,025$. df $=\mathrm{n}-\mathrm{k}-1$ atau $200-2-1=$ 197 (k adalah jumlah variabel bebas dan $\mathrm{n}$ adalah jumlah responden), maka didapat nilai t-tabel adalah 1,972. Nilai t-tabel juga dapat dicari dengan menggunakan Microsoft Excel dengan formula $=\operatorname{TINV}(0,05,197)$.

\section{Tabel 15. Hasil Uji t}

\begin{tabular}{|c|c|c|c|c|c|c|}
\hline \multicolumn{7}{|c|}{ Coefficients $^{a}$} \\
\hline & & Unstandardize & Coefficients & $\begin{array}{c}\text { Standardized } \\
\text { Coefficients }\end{array}$ & & \\
\hline \multicolumn{2}{|c|}{ Model } & $\mathrm{B}$ & Std. Error & Beta & $\mathrm{t}$ & Sig. \\
\hline \multirow[t]{3}{*}{1} & (Constant) & 1,300 & ,337 & & 3,857 & 000 \\
\hline & Kepercayaan &, 734 &, 085 & ,486 & 8,658 &, 000 \\
\hline & Citra Merek & ,495 & 084 & ,332 & 5,916 & ,000 \\
\hline
\end{tabular}

Sumber: data diolah oleh Peneliti (2017)

Berdasarkan hasil uji t pada penelitian ini memiliki nilai signifikan sebesar 0,000 untuk variabel kepercayaan $\left(\mathrm{X}_{1}\right)$ dan 0,000 untuk variabel citra merek $\left(\mathrm{X}_{2}\right)$. Jika nilai t hitung sebesar 8,658 untuk variabel kepercayaan $\left(\mathrm{X}_{1}\right)$ dan nilai t-hitung sebesar 5,916 untuk variabel citra merek $\left(\mathrm{X}_{2}\right)$ dibandingkan dengan nilai t-tabel sebesar 1,972079, maka terlihat nilai t-hitung lebih besar. Dapat disimpulkan bahwa variabel kepercayaan dan citra merek secara parsial mempengaruhi keputusan pembelian mobil Toyota Agya.

\section{Koefisien Determinasi $\left(\mathbf{R}^{2}\right)$}

Analisis determinasi diperlukan untuk mengetahui seberapa besar persentase variabel bebas menjelaskan variabel terikat (Ghozali, 2012:98). Berikut adalah hasil analisis determinasi antara variabel kepercayaan $\left(\mathrm{X}_{1}\right)$ dan citra merek $\left(\mathrm{X}_{2}\right)$ terhadap keputusan pembelian (Y). 
Tabel 16. Hasil Koefisien Determinasi

\begin{tabular}{lrrrr}
\hline \multicolumn{5}{c}{ Model Summary $^{b}$} \\
\hline Model & $\mathrm{R}$ & $R$ Square & Adjusted $R$ Square & $\begin{array}{c}\text { Std. Error of the } \\
\text { Estimate }\end{array}$ \\
\hline 1 &, $686^{\mathrm{a}}$ &, 471 &, 466 &, 96366 \\
\hline \multicolumn{5}{c}{} \\
\hline
\end{tabular}

Sumber: data diolah oleh Peneliti (2017)

Nilai yang digunakan dalam penelitian adalah Adjusted $R$ Square, yaitu sebesar 0,466, jadi sumbangan variabel kepercayaan dan citra merek sebesar $46,6 \%$ sedangkan sisanya sebesar $53,4 \%$ dijelaskan oleh faktor lain yang tidak diteliti.

\section{KESIMPULAN DAN SARAN}

\section{Kesimpulan}

Setelah melakukan analisis data primer mengenai kepercayaan dan citra merek terhadap keputusan pembelian (survei mobil Toyota Agya di wilayah Jakarta), maka dapat diambil kesimpulan sebagai berikut:

1. Pernyataan hipotesis pertama (H1) diterima. Variabel kepercayaan berpengaruh positif dan signifikan terhadap keputusan pembelian mobil Toyota Agya di wilayah Jakarta. Hal tersebut membuktikan bahwa apabila kepercayaan yang diberikan mobil Toyota Agya dapat memenuhi harapan maka akan tercipta keputusan pembelian.

2. Pernyataan hipotesis kedua (H2) diterima. Variabel citra merek berpengaruh positif dan signifikan terhadap keputusan pembelian mobil Toyota Agya di wilayah Jakarta. Hal tersebut membuktikan bahwa apabila citra merek yang diberikan mobil Toyota Agya dapat memenuhi harapan maka akan tercipta keputusan pembelian.

\section{Saran}

\section{Saran Praktis}

1. Terkait dengan implikasi variabel kepercayaan, maka diharapkan bagi pihak perusahaan Toyota khususnya mobil Toyota Agya dapat menyesuaikan 
kestabilan mobil dengan cara memperkuat ban mobil dan power steering agar sistem kemudi menghasilkan putaran kemudi yang ringan. Selain itu juga dapat meningkatkan kualitas body mobil yang kuat dan kokoh dengan menambah lapisan body mobil agar bisa melindungi pengguna.

2. Terkait dengan implikasi variabel citra merek, maka diharapkan bagi perusahaan mobil Toyota Agya atau pengelola di bagian pemasarannya, dapat meningkatkan dan menginformasikan pengenalan tentang spesifikasi merek mobil Toyota Agya kepada pengguna dengan cara mengadakan pameran khusus mobil Toyota Agya. Selain itu perusahaan juga harus menciptakan komunitas dengan cara melibatkan anak muda sebagai pengurusnya dan melakukan kegiatan touring atau gathering.

3. Terkait dengan implikasi variabel keputusan pembelian, maka diharapkan bagi perusahaan mobil Toyota Agya dapat memperkuat identitas mobil, seperti penggunaan logo khusus yang dapat menarik perhatian konsumen dan menciptakan inovasi bentuk body mobil terbaru yang lebih mencerminkan identitas mobil tersebut.

\section{Saran Teoritis}

1. Penelitian ini dapat dilakukan kembali dan dapat digeneralisasikan yaitu dengan objek penelitian yang berbeda dengan mobil Toyota Agya, seperti mobil merek lainnya dengan konsep memenuhi standar kualitas yang cukup. Contoh mobil dengan jenis low cost green car lainnya seperti Daihatsu Ayla, Datsun dan Honda Brio.

2. Penelitian ini dapat dilakukan kembali dengan menggunakan variabel yang berbeda seperti kepuasan pengguna, loyalitas pengguna, minat membeli kembali agar dapat mengeksplorasi kemungkinan variabel lain yang dapat mempengaruhi keputusan pembelian.

3. Penelitian ini dapat dilakukan kembali dengan meneliti jenis otomotif lainnya seperti motor, mobil level yang lebih tinggi, angkutan umum dan kendaraan lainnya. 
4. Penelitian ini dapat dilakukan kembali dengan mengambil ruang lingkup dan jumlah responden yang lebih luas sehingga akan mendapatkan tanggapan yang berbeda.

\section{DAFTAR PUSTAKA}

Albert. (2014). Metode Riset untuk Ekonomi dan Bisnis, Teori Konsep dan Praktik Penelitian Bisnis (Dilengkapi Perhitungan Pengolahan Data dengan IBM SPSS 22.0). Bandung: Penerbit Alfabeta.

Assistant Professor Mohammed Alamgir. Lecturer Tasnuba Nasir. Associate Professor Mohammad Shamsuddoha. Associate Professor Ph.D. Alexandru Nedelea. (2015). Influence Of Brand Name On Consumer Decision Making Process-An Empirical Study On Car Buyers. Chicago., 5 (3), 143-144.

Eze, Uchenna Cyril. Yee, Kwan Pay. Wamala, Fenella. (2012). Journal of Analyzing the Intention to Purchase Proton Automobiles: Preliminary Findings, Contemporary Management Research, 8 (4), 267 - 274.

Gaikindo. (2011). Perkembangan Industri Otomotif. Diakses dari http://www.gaikindo.or.id/perkembangan/ pada tanggal 25 November 2016.

Ghozali, Imam. (2012). Aplikasi Multivariate dengan Program IBM SPSS 20. Semarang: Badan Penerbit Universitas Diponegoro.

J. Paul Peter \& Jerry C. Olson. (2000). Perilaku Konsumen dan Strategi Pemasaran (5 ${ }^{\text {th }}$ Edition). Jakarta: Penerbit Erlangga.

Katadata.co.id. (2016). Penjualan Mobil di Indonesia. Diakses dari http://katadata.co.id/grafik/2016/01/04/penjualan-mobil-indonesiatertinggi-di-asean pada tanggal 25 November 2016. 
Khan, Farshid Haji Khodaverdi. Supinit, Vijit. (2014). What Affects the Buying Decision of a Car in Thailand: International Journal of Social Science and Humanities Research, 3 (4), 453.

Kim, Jeong Min. (2016). The Brand Images Analysis of Korean and German CarsBased on Big Data. International Journal of Software Engineering and Its Applications, 2 (1), 163.

Kotler, Philip. Keller. (2009). Marketing Management (12 ${ }^{\text {th }}$ Edition). Manajemen Pemasaran. Terjemahan Slamet Riyadi. Jilid 2. Jakarta: PT. Indeks.

Kuncoro, Mudrajat. (2007). Metode Kuantitatif: Teori dan Aplikasi untuk Bisnis dan Ekonomi. Yogyakarta: UPP STIM YKPN.

Malhotra, Naresh K. (2010). Marketing Research (6 ${ }^{\text {th }}$ Edition). Riset Pemasaran. Terjemahan Surdan. New Jersey: Prentice Hall.

Mamahit, Philius. (2005). Pengaruh Brand Image, Brand Trust, dan Kualitas Produk Terhadap Keputusan Pembelian Mobil Toyota All New Yaris Pada PT. Hasjrat Abadi Manado. Marketing Journal, 15 (5).

Priyatno, Dwi. (2010). Teknik Mudah dan Cepat Melakukan Analisis Data Penelitian dengan SPSS. Yogyakarta: Gava Media.

Robhi, Farruq. (2013). Pengaruh Kepercayaan (Trust) dan Atribut Produk Terhadap Sikap dan Perilaku Produk. Universitas Sumatera Utara., 2 (1), 321.

Sinarwati. Madjid, Rahmat. Alamsyah, Andi Adry. (2014). The Roles of Behavioral Control and Trust toward Samsung Smartphone Purchase Decision (An Empirical Study in Management Department Student Halu Oleo University). International Journal of Science and Research (IJSR). 2319-7064, 2210. 